\title{
THE SUBARACHNOID DISSEMINATION OF SPINAL TUMOURS*
}

\author{
BY
}

\section{J. E. A. O'CONNELL}

\author{
(St. Bartholomew's Hospital, London) \\ (RECEIVED 18TH APRIL, 1946)
}

THE occurrence of diffuse tumours in the subarachnoid space has been recognized in the literature since the description of sarcomatosis of the meninges by Ollivier in 1837 . It was long, however, before the neuroglial nature of many of these tumours was appreciated. The classification of the gliomata by Bailey and Cushing (1925) and the description by these authors of the clinical and pathological features of the cerebellar medulloblastomata shed much light upon the problems of this diffuse tumour formation. Once the tendency for medulloblastomata to spread through the subarachnoid space had been recognized, it became obvious that many of the previously reported cases of sarcomatosis and gliomatosis were in reality examples of this type of cerebellar growth exhibiting its malignant potentialities. Later it was recognized that other intracranial gliomata might spread to the spinal subarachnoid space. In 1931 Cairns and Russell described the occurrence of metastases in the spinal subarachnoid space in eight cases of intracranial tumour. In addition to medulloblastomata this group included examples of glioblastoma multiforme, astrocytoma, and ependymoma. In 1942 Beck and Russell described a group of cases of oligodendrogliomata in which spread had occurred to the spinal subarachnoid space from a primary cerebral tumour. The spread of intracranial tumours through the subarachnoid space to the spinal canal is thus widely recognized and, indeed, is by no means infrequent. Perusal of the literature suggests that the spread of primary spinal tumours through the subarachnoid space to the cranium is an infrequent and less well recognized occurrence. In 1908 Mallory briefly refers to his having observed a child with a gliomatous tumour of the lumbar spinal cord which had spread throughout the subarachnoid space and over the cerebrum and cerebellum. Rutimeyer described in 1930 a case of intramedullary tumour in the lower cord which had spread through the subarachnoid space to the cervical region. In 1934 Greenfield described a glioma which arose in the spinal canal in relation to the cauda equina and spread in the form of isolated nodules throughout the spinal and cranial subarachnoid space. It was a paper by Eden in 1938 that brought the subject to my notice. Eden

* A paper read by title at the meeting of the Society of British Neurological Surgeons in February, 1946. gives a detailed account of a case in which widespread dissemination of a spinal tumour had occurred throughout the whole subarachnoid space, and he reports that Förster had had experience of a similar case. During the last three years three cases have been admitted to our unit, two of which appear to be certainly, and one possibly, examples of the subarachnoid spread of spinal tumours. The clinical and pathological findings in these cases forms the basis of this communication.

Case 1.-G. P., a little girl of $5 \frac{1}{2}$ years, was admitted on 6th January, 1943. Her mother stated that she had been well in every way until six months previously. Then it was noticed that she had become nervous and she refused to be separated from her mother. Soon she began to tire easily and frequently rested when at play. Shortly afterwards the child commenced to have pains in both groins-especially towards evening. They sometimes caused her to wake crying in the night. Within a month of the onset of her symptoms she was put to bed. Pain in the lumbo-sacral region soon appeared and her mother noticed that the child could move first her left and later her right leg only by lifting them with her hands. Loss of vesical and rectal control appeared at the same time. In due course the child was admitted to hospital. Here she was found to have a flaccid paraplegia with total loss of sensibility below the lower abdomen. It was further noticed that she had increased sweating above that level and a pustular rash over the left chest and abdomen. After certain investigations to be described she was transferred to this unit six months after the onset of her illness. Her past and family history revealed nothing noteworthy. Examination showed a bright happy little girl. There was no abnormality in the cranial nerves or upper limbs. Examination of the spine showed no overlying cutaneous abnormality or deformity. There was slight lower dorsal tenderness. There was a flaccid paralysis of the lower extremities and Beevor's sign was positive. There was a loss of all forms of sensibility below the 8th dorsal segment on the left and the 11th dorsal segment on the right. The lower abdominal reflexes were absent and no plantar responses were obtainable. It was also obvious that there was a loss of sweating below the level of the lesion, whereas above it sweating was so marked as to be excessive, and that the skin of the feet and sacral region was blue. The remains of the pustular rash which had affected the left side of the trunk was visible. A diagnosis of a tumour extending from approximately the 10th dorsal segment to the conus was made. It was considered likely that this tumour was intramedullary. Before the child's admission lumbar puncture and a cisternal myelography had both been carried out. The former was reported on as a dry puncture and the latter revealed a complete block with its upper limit at the 10th dorsal vertebra. Radiography had shown in addition a spina bifida involving the spines of the 2 nd, 3rd, 4th, and 5th lumbar vertebræ as well as 
the sacrum, with decalcification, erosion, and separation (transversely) of the lumbar pedicles.

Laminectomy was carried out-the spines and laminæ of the 11th and 12th dorsal and first lumbar vertebræ being removed, together with the maldeveloped laminæ and spinal rudiments of the 2 nd lumbar vertebra. There was little epidural fat, and pulsation of the theca was present only superiorly. On opening the tense dura, the underlying cord was seen to be replaced by a solid tumour, over the surface of which ran tortuous vessels. Aspiration revealed that the mass was non-cystic, and the wound was therefore closed leaving the dura open.

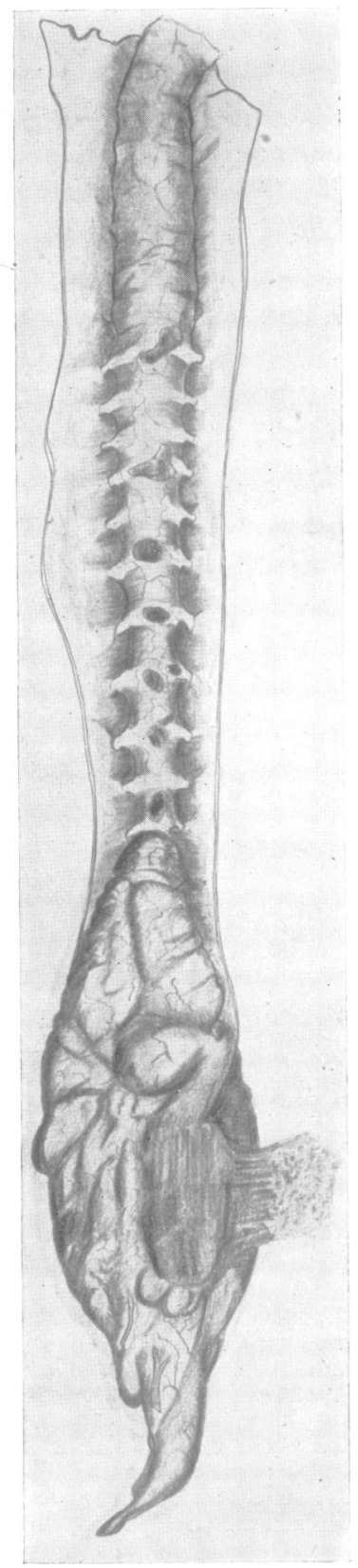

Fig. 1.-Case 1: drawing of post-mortem specimen showing the tumour and the layer of subarachnoid growth which surrounds the spinal medulla throughout its length. The arachnoid sheaths of the spinal nerve roots are distended with neoplasm.

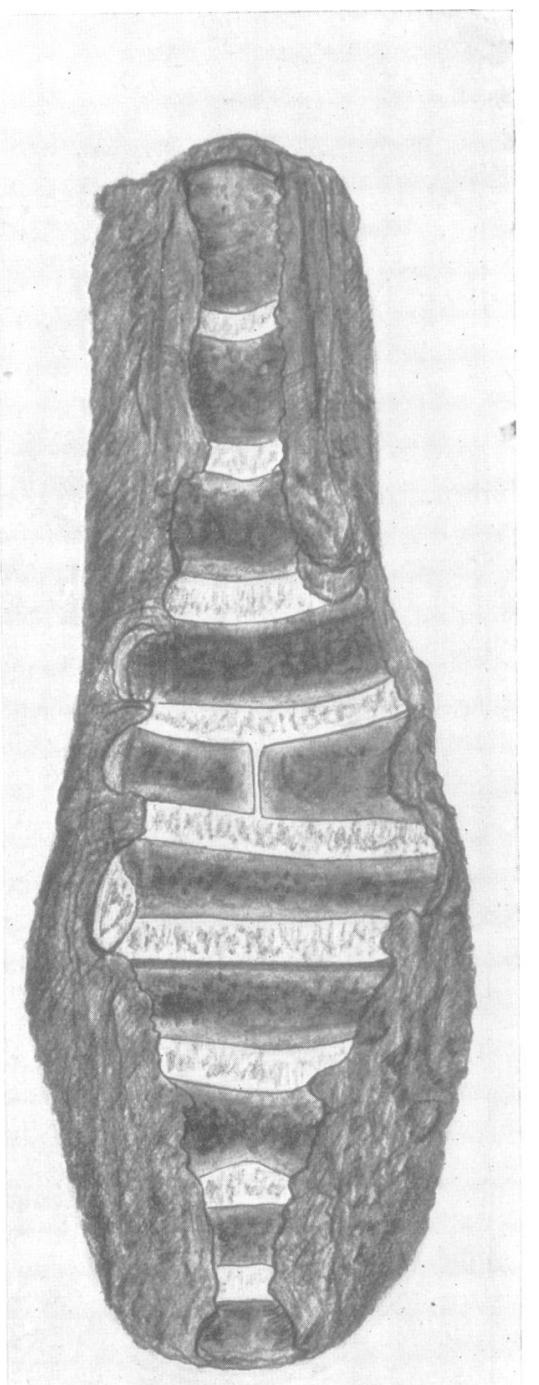

FIG. 2.-Case 1: drawing of the lumbo-sacral spinal canal. It is dilated by the pressure of the tumour, $\mathrm{O}$ and the intervertebral discs have resisted the pressure erosion more successfully than the vertebral bodies.

No biopsy was carried out. The wound healed soundly, $\bar{N}$ and the patient was little disturbed by the exploration. A few days after operation a papular rash appeared on $N$ the left trunk between the 3rd and 11th dorsal seg- N ments. This progressed to pustule formation. Three $\omega$ weeks after operation headache and vomiting appeared, soon to be followed by generalized convulsions repeated 0 several times daily. A peripheral left facial palsy then developed, and with drowsiness deepening into coma, the child died four weeks from the date of the exploration, and seven months from the date of origin of her symptoms.

At autopsy the only abnormality found, apart from $\mathbb{D}$ those related to the central nervous system, was some $\mathbb{\mathbb { D }}$ congestion of both lung bases with hæmorrhages in the 2 


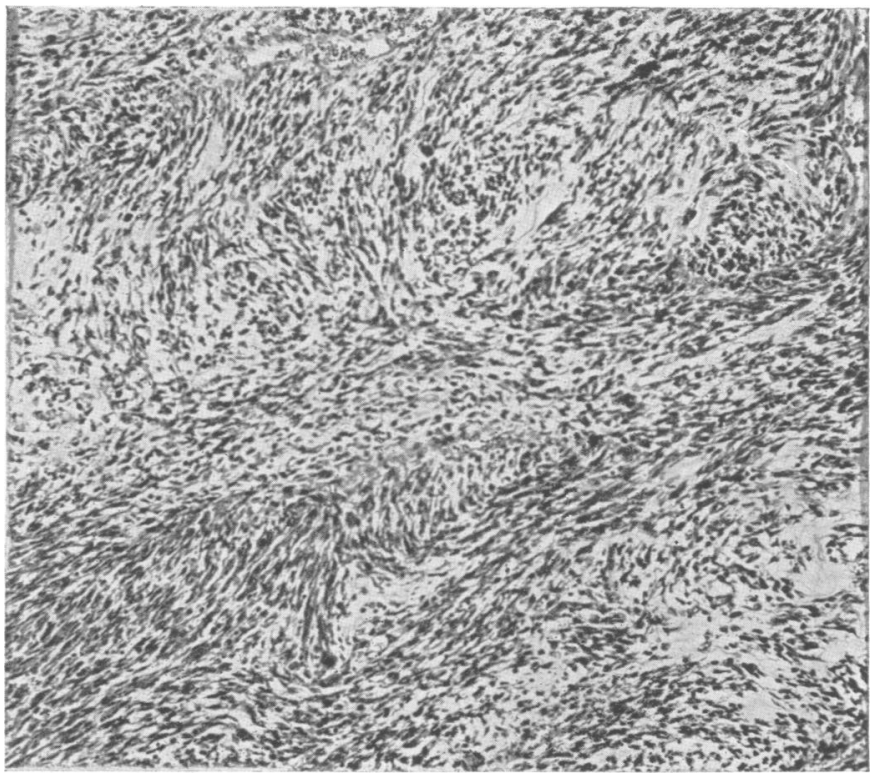

right lower lobe-possibly of asphyxial origin. The spina bifida was found to extend downwards from the operative defect to the sacrum where the laminæ were united by wide cartilaginous bands. On opening the theca the tumour mass was found to entirely fill the spinal canal from the 10th dorsal vertebra to the fundus of the theca (Fig. 1)-measuring $15 \mathrm{~cm}$. in length by $6 \mathrm{~cm}$. in diameter at its maximum girth. The entire spinal subarachnoid space above the level of the main tumour was distended with growth which extended along the arachnoid sheaths of the spinal nerve roots. Pressure atrophy of the surrounding bone had occurred-though it was noticeable that the intervertebral discs were resistant to this compression (Fig. 2). Examination of the brain revealed flattening of the cerebral convolutions and a cisterna magna greatly distended with fluid. The pontine and interpeduncular cisterns were filled with firm opaque white material resembling growth. No abnormality was visible on the surface of the cerebral hemispheres, but on section a mild degree of internal hydrocephalus was present.

Histological examination of the spinal tumour revealed it to be made up of sheets and interlacing bundles of spindle-shaped cells with long processes (Fig. 3). In some areas a definite palisade arrangement of nuclei can be made out. The tumour in the subarachnoid space at the foramen magnum level was made up of similar cells, but more loosely arranged. Had it not been for its rapid growth and uncontrolled spread this tumour might have been regarded as a neurofibroma. This and other features lead to the diagnosis of a neurofibrosarcoma. Further examination revealed, however, that in many of the cell processes a definite cross striation is present, and the tumour is thus a rhabdomyosarcoma (Fig. 4). Doubtless it developed from a teratomatous tumour in relationship with this child's spina bifida.

Case 2.-J. C., aet 16, was admitted on 13th May, 1945, because of weakness of his right leg. His father stated that during the previous twelve months the boy had adopted an increasingly stooped attitude whether standing or sitting. Three months before his admission it was noticed that he dragged his right foot and he refused to wear boots as he found them too heavy. At this time,

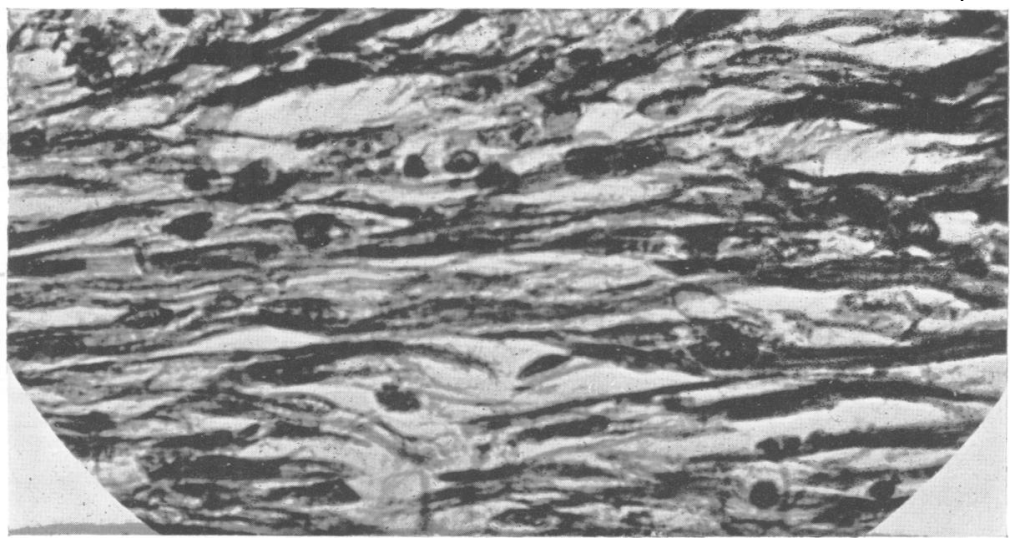

FIG. 4.-Case 1: microphotograph of tumour surrounding medulla oblongata

(P.T.A.H.; $\times 425)$. Cross striation may be seen in some of the cell processes. 


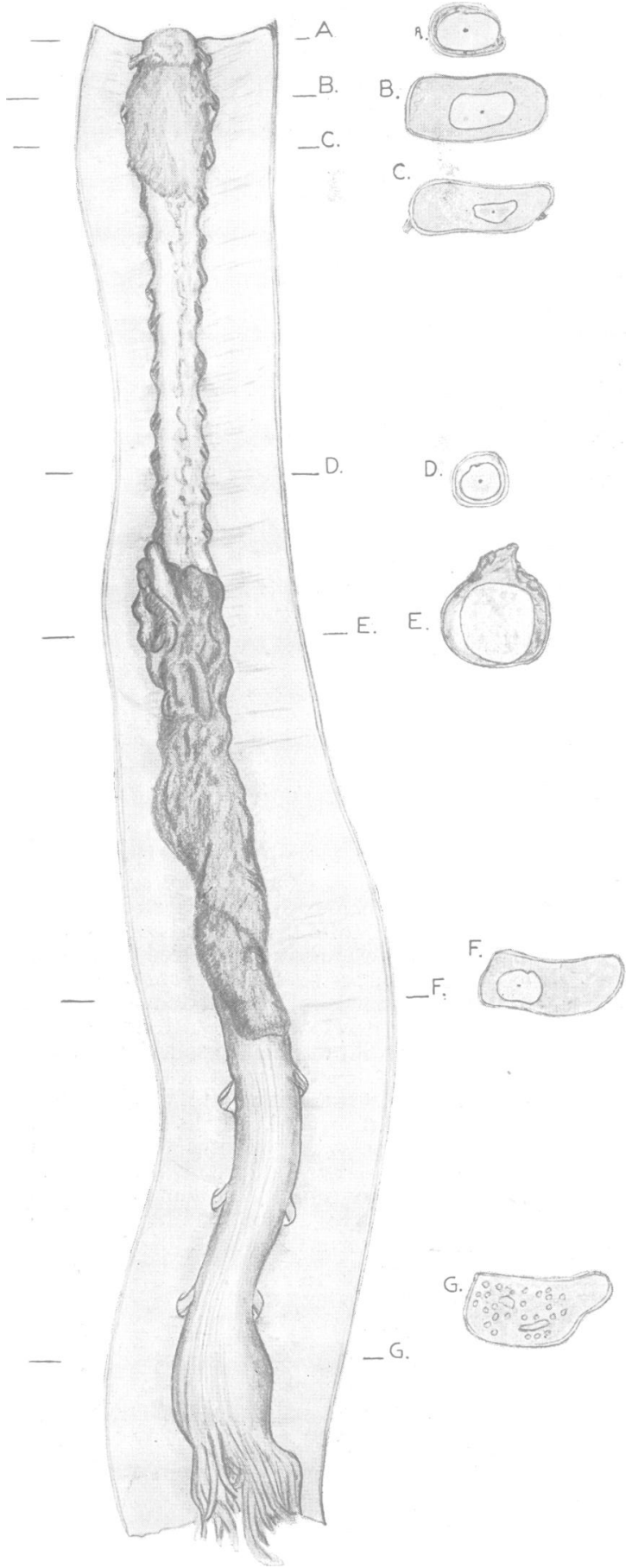

Fig. 5.-Case 2 : drawing of spinal medulla and cauda equina. The primary tumour in lower portion of the spinal medulla and the large sheath of tumour in the cervical region are shown. On the right there are represented transverse sections of the theca and its contents at the levels indicated by letters $A$ to $G$. The continuous sheath of tumour can be seen in all the sections.
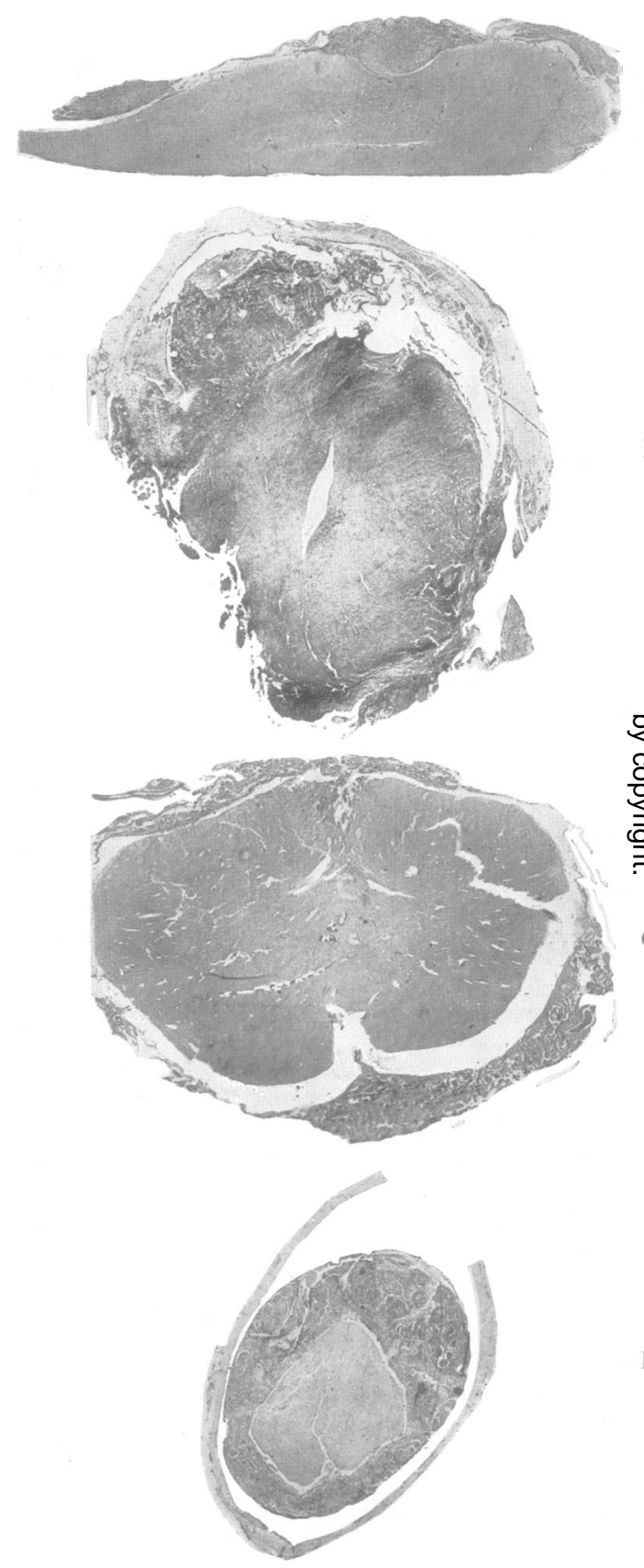

FIG. 6.-Case 2: low-power microphotographs to show subarachnoid tumour at various levels in the cranium 0 and spinal canal. A. interior surface of $\mathrm{Lt}$. frontal lobe. B. medulla oblongata. C. cervical spinal cord. $\&$ D. thoracic spinal cord. 
too, the patient began to complain of left-sided abdominal pain-brought on by the lifting entailed by working in his father's greengrocer's shop. There had been no headache, vomiting, or visual disturbance, and indeed no other symptoms of any description. His parents stated that he had never been seriously ill, but pointed out that while five siblings showed normal mental development, the patient and his twin brother were grossly retarded mentally. Examination revealed a tall thin lad of extremely low intelligence. There was no abnormality in the cranial nerves or upper limbs. The spine showed a marked lower dorsal kyphosis with an increased lumbar lordosis; in addition there was a dorsal scoliosis to the left with a compensatory lumbar

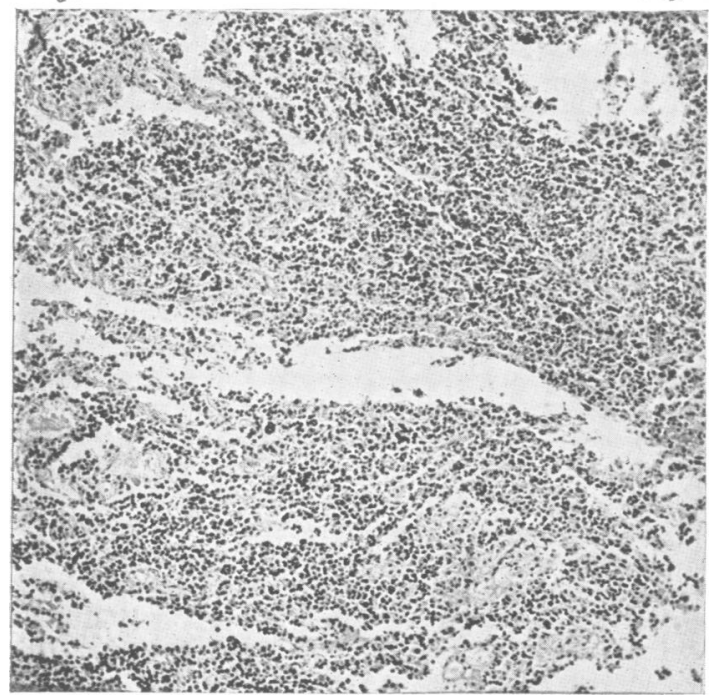

FIG. 7.-Case 2: microphotograph of tumour (H. \& E.; $\times 85)$.

curve to the right. Beevor's sign was positive, and there was a spastic paresis of the right leg-more severe at the periphery. Power in the left leg was normal. Sensation was tested with difficulty owing to the patient's extremely low intellectual capacity. It seemed probable that pain and temperature sensibility were diminished on the left leg, and vibration and postural sensibility reduced on the right. The lower abdominal and cremasteric reflexes were absent. The tendon reflexes in the lower limbs were brisk with sustained clonus on the right, and both plantar responses were extensor. Lumbar puncture revealed a complete subarachnoid block, and the c.s.f. exhibited Froin's syndrome. In addition, on two occasions 10 cells described as lymphocytes were reported to be present. While radiography of the spine showed only the spinal deformity, a myelogram revealed a complete block with the lower limit of the lesion at the 10th dorsal vertebra. A diagnosis of an intramedullary tumour was made, but exploration decided upon. A laminectomy from D6-D12, inclusive, revealed a long intramedullary tumour without disclosing its upper or lower limits. Biopsy was not performed and the dura was left open. After a normal convalescence the boy was given a course of $x$ radiation. He received a total dosage of 7,500 r., but in spite of it his condition deteriorated rapidly. He became restless and noisy and developed a spastic paraplegia. He showed evidence of pulmonary infection with high fever, tachycardia and rapid respirations, and finally died four months after the exploration and sixteen months from the date of onset of his symptoms.

At post-mortem examination the only abnormality found outside the central nervous system was consolidation of the middle and lower lobes of the left lung and extensive pressure sores. When the spinal canal was opened the whole spinal theca was seen to be filled with tumour tissue (Figs. 5-6). The main mass of tumour extended from the 7 th dorsal segment to the conus, and filled the theca below this level so that the roots of the cauda equina were buried in it. Above the 7 th dorsal segment the cord was enveloped by a thin layer of growth which filled the subarachnoid space, and a thickening of this sheath of tumour tissue was present at the level of the 3rd cervical segment. The spinal cord was recognizable within the sheath of tumour cells throughout its length, though the differentiation was least obvious in the dorso-lumbar region.

Within the cranium it was found that the pontine and interpeduncular cisterns were filled with a white opaque layer of growth which extended into the lateral fissures and spread in the sulci on to the lateral and inferior surfaces of the cerebral hemispheres. The ventricular system showed a mild degree of dilatation, and there was a nodule of tumour in the right lateral ventricle close to the foramen of Munro. Meckel's cave on the left was filled with growth.

Histologically the tumour proved to be a highlycellular glioma in which there was considerable pleomorphism (Figs. 7 and 8 ). There was no reticulin formation and collagen was present around the blood vessels only. It has been classified as a glioblastoma multiforme. It is believed that it arose primarily in the lower dorsal cord and subsequently involved the subarachnoid space-first in the spinal canal and later in the cranium. From the latter, spread had occurred to the right lateral ventricle.

Case 3.-H. F., a girl of 16 years, was admitted on 16th December, 1943, complaining of headache and lower back pain. Her mother stated that the girl had been in her usual health until five months previously. Then it was noticed that she walked with a stoop-mainly affecting her lower back-and that she was unsteady on her feet-staggering to both sides " as though she were

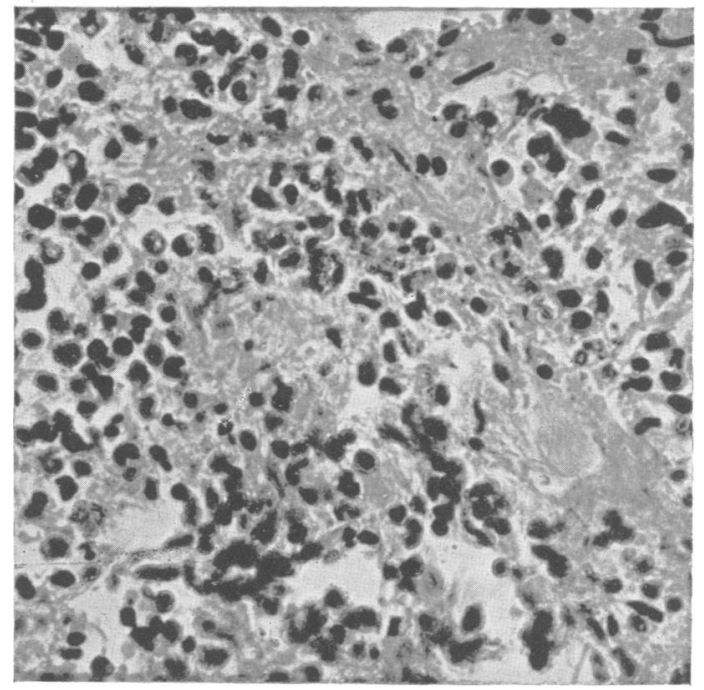

FIG. 8.-Case 2: microphotograph of tumour (H. \& E.; $\times 425)$.

drunk." Three months before admission she complained of backache and headache. The latter was particularly severe on waking and was associated with vomiting. She continued to work for six weeks in spite of her symptoms. Then, however, her headache became extremely severe and persistent. She screamed a great deal, was frequently irrational, and visual deterioration developed with diplopia. There had been no loss of consciousness and no weakness of the upper limbs, though her unsteady gait had been attributed to 
weakness of her legs. She had complained of numbness in all her limbs, and in the weeks immediately before her admission had had pains in her abdomen and feet -in addition to the head and back pain previously present. There had been no sphincter disturbance, and there was nothing noteworthy in her past or family history. Examination revealed a tall, ill, under-nourished girl. She complained continuously of widespread pains and of other subjective sensory disturbances in her limbs. Her mental state was such as to prevent her co-operation in the neurological examination. The cerebellar fossæ bulged and there was some neck rigidity. There was high bilateral papillœdema with hæmorrhage and exudate and greatly reduced visual acuity on the left. There was bilateral limitation of lateral gaze with a coarse horizontal nystagmus to both s:des and no other cranial nerve abnormality. No weakness or disturbance of tone or co-ordination was found in the upper limbs. The girl complained of inability to move her legs, but did so readily on stimulation. No definite sensory defect could be made out, perhaps because co-operation was poor. All the tendon reflexes were obtained weakly. The abdominal reflexes were absent and the plantar reflexes were equivocal flexor responses. Routine general examination showed no abnormality, and skull films were normal. A diagnosis of intracranial tumour-possibly in the cerebellar vermis-was made, and ventriculography performed under general anæsthesia. This revealed a moderate internal hydrocephalus which involved the $3 \mathrm{rd}$ and 4 th ventricles (Fig. 9). An immediate suboccipital exploration was done. The cerebellar hemispheres and vermis were of normal appearance and consistency, and there was no tonsillar herniation. The cisterna magna was greatly dilated and full of oxygen. The arachnoid forming its posterior wall was thick and opaque. It was opened and the 4th ventricular region examined by separation of the tonsils. No tumour was found, and a soft rubber catheter was passed readily into the 3 rd ventricle. The wound was therefore closed. Post-operatively headache was relieved and her vision improved. Her mental state also showed improvement, and an atonic

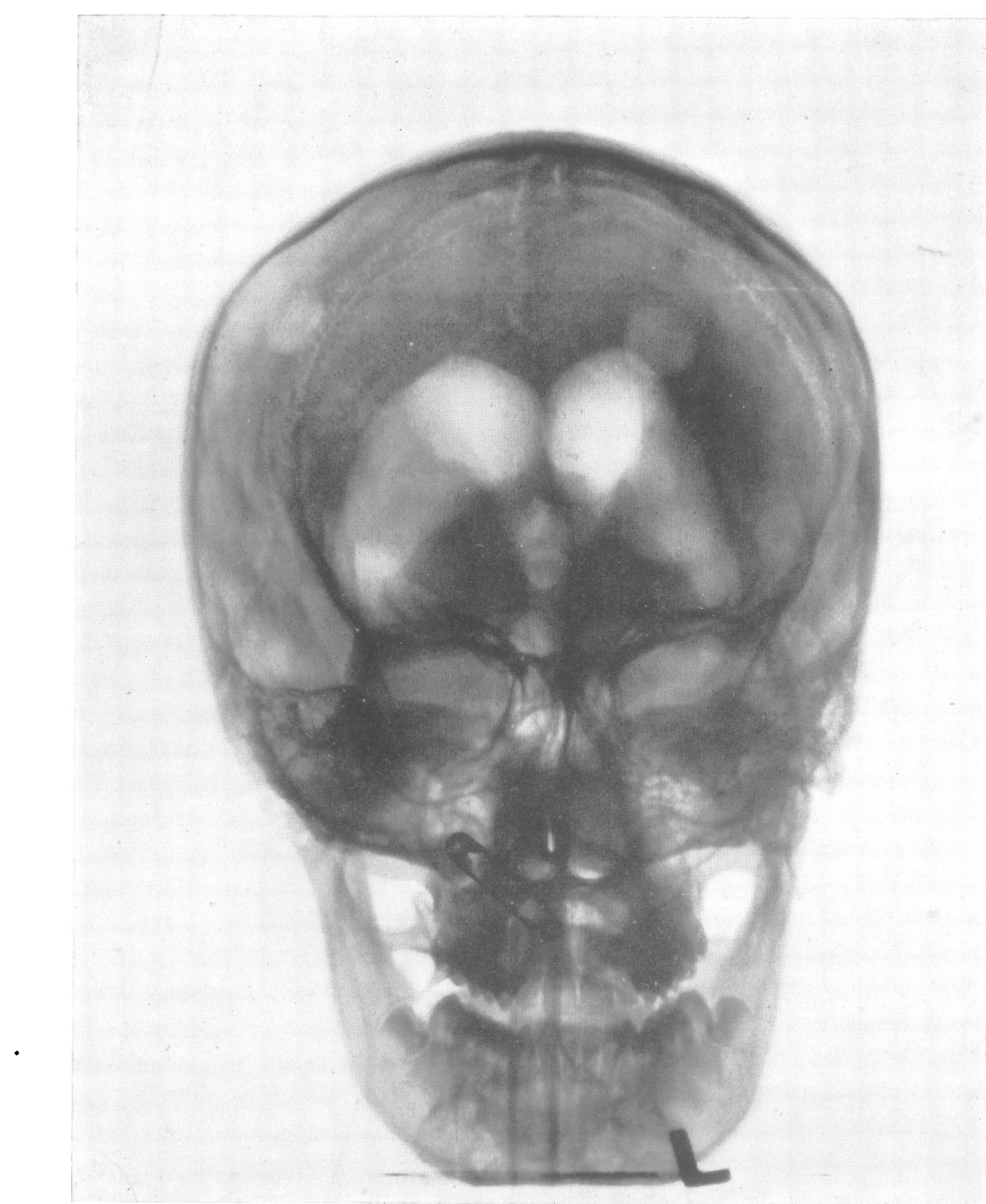

Fig. 9.-Case 3: ventriculogram (postero-anterior) showing dilated aqueduct and fourth ventricle. 
paralysis of the lower extremities was soon apparent, with analgesia and anæsthesia below the 10th dorsal segment. The tendon reflexes could not be obtained in the lower limbs, and the plantar responses were extensor. There was complete loss of sphincter control. Lumbar puncture showed a complete subarachnoid block with $2.4 \mathrm{~g}$. of protein per $100 \mathrm{c}$.cm. of c.s.f. and 24 cells described as lymphocytes. A lipiodol myelogram revealed the lower limit of the complete block to be at the level of the 10th dorsal vertebra. Exploration was decided upon, and the spines and laminæ from the 6 th to the 10th dorsal vertebra removed. On opening the dura mater an intramedullary tumour was found to occupy that portion of the cord which lay posterior to the bodies of the 7 th to the 9th dorsal vertebræ. Pressure on the suboccipital decompression area gave rise to a free flow of cerebrospinal fluid from the subarachnoid space at the upper end of the laminectomy wound. A biopsy was carried out and the wound closed, leaving the dura open. After this procedure there was no improvement in the function of the lower limbs, and two months later at her parents' request she was transferred to a hospital near her home, where she died after a further two months without a post mortem being obtained. The total duration of her illness had been 10 months.

Examination of the biopsy material from the spinal tumour revealed a cellular growth (Figs. 10 and 11). The majority of the cells were spindle shaped, but pleomorphism was present with some multinucleated giant cells. Small lymphocytes occurred in places. No reticulin was present, and collagen was found in relation to the blood vessels only. There has been discussion as to whether this tumour should be classified as a medulloblastoma or a glioblastoma multiforme, and on the whole the latter diagnosis has been more favoured. It must thus be admitted that the evidence that this case is to be regarded as one of intracranial spread of a primary spinal tumour is incomplete. An alternative view would be that the primary tumour had been an intracranial medulloblastoma and that the spinal tumour was due to subarachnoid dissemination of the former. This is a definite possibility, but against it

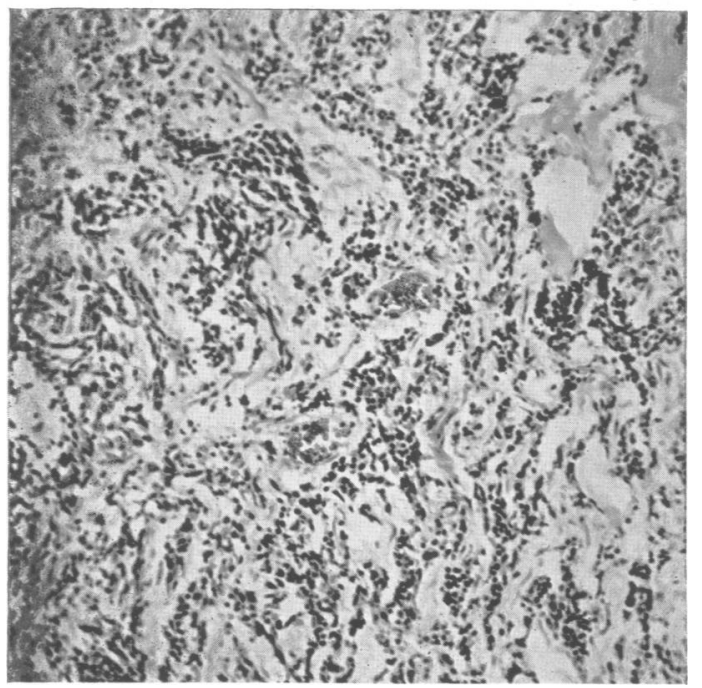

FIG. 10.-Case 3: microphotograph of biopsy material (H. \& E.; $\times 85)$.

may be raised the fact that a full exploration of the posterior fossa (without splitting the vermis) revealed no evidence of tumour here-the cisterna magna being large and there being no tonsillar herniation. Further, the ventriculographic appearances suggest subarachnoid

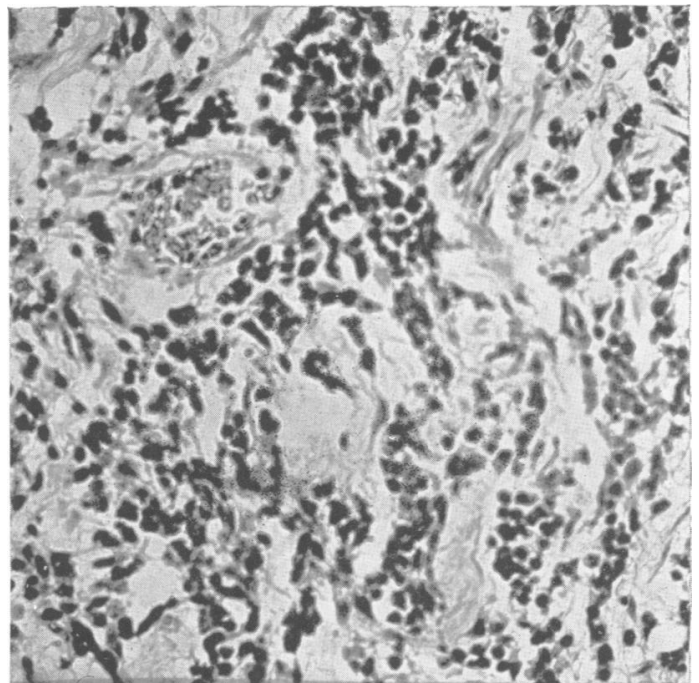

FIG. 11.-Case 3: microphotograph of biopsy material (H. \& E.; $\times 260$ ).

obstruction as the cause of the hydrocephalus. Had a biopsy been done on the thickened arachnoid of the posterior fossa, and had it been found to be infiltrated with growth, the evidence would clearly point to subarachnoid tumour formation as the cause of the internal hydrocephalus.

\section{Discussion}

These three patients were seen in the course of a three-year period. This suggests that the subarachnoid dissemination of spinal tumours is a less uncommon occurrence than references to it in the literature would lead one to believe. If this be true, it is but what one might expect from the known behaviour of tumours involving the vessels through which either blood or lymph circulates. It is recognized that spread of neoplasm through these latter channels is the main obstacle to the successful treatment of malignant disease. While the circulation of the cerebrospinal fluid-the third circulation as it has been called-may be a less forceful one than that of the blood it would be strange if a tumour projecting into the cerebrospinal fluid pathways never utilized them as a route of spread. It seems that dissemination through the spinal subarachnoid space is frequently by permeation. When the advancing head of the growth reaches the cranium it encounters maximal pressure fluctuations within the basal cisterns and the ebb and flow of cerebrospinal fluid to which they give rise. This may be responsible at times for the distribution of groups of cells as emboli throughout the cranial subarachnoid space and ventricular system. The appearances in case 2 suggest this.

Clinically these cases exhibit points of interest. They were all in early life-the sarcoma occurring in a girl of $5 \frac{1}{2}$ years old, and the two gliomata in adolescents. The total duration of the illness in these three cases was 7 months, 16 months, and 10 months. Certain features of the cases may be of diagnostic importance. When the tumours 
gained the cranial subarachnoid space, obstruction to the cerebrospinal fluid circulation occurred, with the development of an internal hydrocephalus and evidence of raised intracranial pressure. Again, the subarachnoid tumour appeared to be capable of giving rise to paralytic or irritative phenomena in related nervous tissue. The former symptoms are doubtless the result of compression or invasion of nervous tissue, and as an example may be mentioned the facial palsy in case 2. The irritative symptoms may take the form of herpes, widespread pains, or other subjective sensory disturbance (posterior roots) or hyperidrosis (anterior roots). From the diagnostic point of view it should in most cases be a fairly simple matter to decide whether a primary cranial tumour has metastasized to the spinal canal or a primary spinal tumour has metastasized to the cranium. Cases will sometimes be seen in which it is difficult to decide where the primary tumour may be-especially if the cranial symptoms and signs overshadow the spinal ones. Case 3 is an example of the difficulty which may arise. It is noteworthy that in the two cases submitted to lumbar puncture in this unit an excess of cells, described as lymphocytes, was reported in the cerebrospinal fluid. It seems possible that further examination might have revealed these " lymphocytes" to be in reality tumour cells. Thus, where subarachnoid dissemination of tumour is suspected, a search for tumour cells in the cerebrospinal fluid might be helpful. Further, an unexplained increase in the lymphocytes in the cerebrospinal fluid in the presence of a spinal tumour might suggest subarachnoid spread. Lastly it may be pointed out that case 1 illustrates an unusual and an additional hazard of the child with a congenital abnormality of the lumbo-sacral region.

\section{Summary}

1. A description is given of the clinical and pathological findings in three cases in which it is believed that widespread subarachnoid dissemination of spinal tumours had occurred.

2. It is pointed out that the occurrence is probably less uncommon than is generally realized, and clinical features which might lead to its recognition are discussed.

In conclusion I should like to express my gratitude to those upon whose assistance these remarks largely depend. Dr. A. Stansfield prepared the histological material, and his co-operation has been of greatest value. Mr. J. Seymour has given valuable assistance with his drawings. Lastly I am indebted to Dr. Dorothy Russell for her kindness in examining the histological material and for giving us her opinion as to the nature of these tumours.

\section{REFERENCES}

Bailey, P., and Cushing, H. (1925). Arch. Neurol. Psychiat (Chicago), 14, 192.

(1926). Tumours of the Glioma Group. Philadelphia.

Beck, D. J. K., and Russell, D. S. (1942). Brain, 65, 352.

Cairns, H., and Russell, D. S. (1931). Ibid., 54, 377.

Eden, K. C. (1938). Ibid., 61, 298.

Greenfield, J. G. (1934). J. Path. Bact., 38, 11.

Mallory, F. B. (1908). J. exp. Med., 10, 575.

Ollivier, C. P. (1837). De la moelle épinière et de sesô maladies. Paris.

Rutimeyer, - - (1930). (Quoted by Eden.) 